\title{
Application of Solution-Focused Brief Therapy (SFBT) to Help Clients with Anxiety Issues
}

\author{
Rabi'atul Adawiyah Haron ${ }^{1}$, Abu Yazid Abu Bakar ${ }^{2 *}$, Kadek Suranata ${ }^{3}$ \\ ${ }^{12}$ Faculty of Education, National University of Malaysia, 43600 Bangi, Selangor, Malaysia \\ ${ }^{3}$ Departement of Guidance Counseling, Universitas Pendidikan Ganesha, Singaraja, Bali, Indonesia, \\ kadek.suranata@undiksha.ac.id \\ *Corresponding author, e-mail: yazid3338@ukm.edu.my, adawiyah123@gmail.com
}

Received 2020-25-04; Revised 2020-05-06; Accepted 2020-05-07; Published Online 2020-05-30

\section{Conflict of Interest}

Disclosures:

The authors declare that they have no significant competing financial, professional or personal interests that might have influenced the performance or presentation of the work described in this manuscript.

\begin{abstract}
The counseling services were created to help people deal with life's problems in more effective ways. Various theories and approaches have been introduced so that practitioners are more confident and have directions in carrying out their duties. Solution-Focused Brief Therapy (SFBT) is one the approaches that views individuals have inner strengths and can deal with the problems they are facing in their daily lives. Feeling anxious is everyone's normal emotion. However, for some people, this anxiety can disrupt their life. This concept paper examines whether the Solution-Focused Brief Therapy (SFBT) is suitable to be applied for clients who suffer from anxiety issues in life.
\end{abstract}

Keywords: Counseling, anxiety, Solution-Focused Brief Therapy, Malaysia 


\section{Introduction}

The existence of counseling services and programs are intended to help people deal with problems, and have positive impacts on themselves and those around them. Various misconceptions have existed in counseling in Malaysia, as counseling is still considered new provision and has not been widely accepted by the community. The common impression is that people who go to see counselors are people who have attitude problems or negative behaviors. In addition, to the extreme, individuals who tend to see counselors are perceived as having mental illnesses. Hence, exposure, understanding, and awareness must be given to the community to correct these misconceptions, and open up the minds of the society to accept and understand the importance of counseling services in an increasingly challenging era of globalization nowadays.

Individuals of different ages will not miss out on various issues in all aspects of life. From birth to present, human beings have evolved from trivial to challenging issues. Of course, various ways have been applied to address these issues. However, not all of the methods used are appropriate and proper. Sometimes, people unknowingly choose the wrong way that results in negative effects such as bland social relationships, prolonged stress, and maybe even unwarranted depression in themselves and the surrounding community. These are the negative things need to be avoided in order to uphold a psychologically healthy life in society. As the saying goes, prevention is better than cure.

Everyone will experience stress and anxiety issues once in a lifetime or more. We will feel depressed when we are faced with a sad event. Feeling depressed is normal, but keep in mind that if left unchecked and treated properly, it is possible that stress may change to a more serious level of anxiety disorder that affects the health of the individual.

The founder of Solution-Focused Brief Therapy (SFBT) is Steve de Shartzer and his wife, Insoo Kim Berg, both of whom are psychotherapists. Together they established the Brief Family Therapy Center in Milwaukee, Wisconsin, where de Shartzer trained in music and played saxophone. He then went on to study at the University of Milwaukee, Wisconsin, and was awarded a Bachelor in Fine Arts and MSc in Social Work. He has authored six books translated into 14 languages and Keys to Solution in Brief Therapy (1985), Clues: Investigating Solutions in Brief Therapy (1988) and Words were Originally Magic (1994), are among his influential writings. In addition, he also produces articles and lectures internationally.

His wife, Berg, has authored and published many scholarly books, including Working with the Problem Drinker: A Solution-Focused Approach (1992) and Family Based Services: A Solution-Focused Approach (1994). He writes based on his experience in applying solution-focused theory on alcohol addicts, marriage therapists, and the poor. De Shazer died in 2005 and 16 months later his wife, Berg, followed. The Brief Family Therapy Center was closed following the death of both of its founders in 2007 and was acquired by the Solution Focused Brief Therapy Association (Sumari et al., 2014).

\section{Discussion}

Each theory and approach to counseling has its own view in the eyes of man. Solution-Focused Brief Therapy (SFBT) sees an individual as having the inner strength and ability (Kraft, 2012; Roeden et al., 2011) to cope with life's challenges. Moreover, according to (Sumari et al., 2014), there are times when people are not bothered by the problems they face.

The SFBT approach is optimistic towards humans and considers the person to be an expert in solving its own issues. They only need guidance and guidance to enable them to be intellectually able and to see alternatives and to suit them. (Bannink, 2007) further explains that individuals are experts based on, else."

"If it is not broken, do not fix it; if something works, continue with it; if something does not work, do something

From a theoretical point of view of humanity, there are some basic principles or assumptions in this theory. One is that the individual is an expert on himself, every single thing he does affects others, small changes can lead to greater changes (Bannink, 2007; Dermer. et al., 2012; Sumari et al., 2014), focusing on positive and future aspects or in other languages achieve a goal that can lead clients to find a solution 
(Sumari et al., 2014); Panayotov, Anichkina, Strahilov; (in Roeden et al., 2011), each individual, his or her own relationships, and the situation is unique (Dermer. et al., 2012), each problem arises, the therapist collaborates with the client in formulating a problem-solving strategy (Sumari et al., 2014).

Each client will come up with different goals and be different from each other despite the similarities. However, one of the goals of therapy for clients is to bring clients to identify the source of their strengths and to change the way they view and treat their problems. This approach seeks to encourage clients to focus less on the problem but on finding a solution and the desired change. Discussing the solution will make the client think of a solution and if the problem is discussed then the client will see that it is a problem and only think of the problem without doing anything. That's what you want to achieve, the solution.

There are several techniques introduced by de Shartzer and Berg where they encourage clients to look at the way they have done and the results they have gained and to help clients find new alternatives through discussion. All in all, de Shartzer emphasizes on problem solving by building good cooperative working relationships between therapists and clients, focusing in the internal strength of the clients and its' sources, exploring changes before therapy starts, asking exceptional questions, magic or miracle questions, and scaling questions, formulating first session task (FSST), and giving therapists' feedbacks to clients. (Dermer. et al., 2012; Sumari et al., 2014).

Frequently asked questions are more about thinking of solutions rather than focusing on problems that arise. In building collaborative relationships between therapists and clients, therapists should be prepared to create conducive and therapeutic workspaces that encourage clients to have more open and open discussions to think about effective outcomes.

Exceptional questions lead clients to identify when or where the problem does not exist. Examples of possible questions are "Have you ever found that this problem does not bother you? Can you explain when it doesn't bother? ". The therapist must be wise and know how to use the skills of asking questions to the client as well as the need to diversify the force said.

Miracle questions are used to encourage clients to see and imagine the difference they would face if the issue was resolved. Clients will be left to fantasize as a way to identify the change they want. There are several benefits to using magic questions including that we can open up possibilities for change in the future. Having anxiety or panic anxiety might be asked, given a scale of 1 to 10, at what level of anxiety did you first come to a session? Next, determine where you are at which level and where we will see changes for client-defined scale changes.

In the last session, the counselor will provide feedback to the client. There are three basic parts to the structure of the formulation: praise, bridge, or task suggestions. Sincere praise can guide clients toward solutions. A bridge or bridge is a rational matter between praise and duty. Task observation is the selfmonitoring process in which the client will identify the difference that occur when it gets better of cognitive, affective, and behavior.

Anxiety is usually caused by uncontrollable stress. We assume that stress is normal when it comes to us with events such as road congestion, workload, etc. We realize that when we are under stress and we cause unstable emotions, it causes thoughts that get worse, which can cause mental health problems. Everyone will react differently to the same situation. There can be under pressure as congestion then cross was positively and some are not. Some signs can be seen in people with anxiety disorders. Among them are anxiety and three or more somatic or cognitive symptoms. According to Wood, McLeod, Piacentini and Sigman (2009).

The application of Solution-Focused Brief Therapy (SFBT) is used to treat anxiety disorders according to several phases of implementation. First, the counselor should build a good working relationship with the client and subsequently create a conducive, therapeutic atmosphere and make the client comfortable. This therapeutic atmosphere can encourage clients to tell the story and trust the counselor. Therapists may choose the interventions proposed in this theory.

The counselor can see that the client has the potential to change to a positive cloud when he or she attends a designated session. This is a good step and in this first meeting, the counselor can ask if the methods that have been or are being made to bring it back I had concerns that it faces. If a client is engaged 
in a particular method and is seen to be appropriate and positive, encouragement will be given for the client to continue. This can drive clients to a stronger business.

Furthermore, we believe that every disturbance experienced will have its time and that it will not appear or interfere with our lives. This exploration will make clients aware that the problem does not exist and that it is out of control. This allows clients to find strength and choose the solution. This method can be implemented in a short period and requires good cooperation between the counselor and the client.

The limitation of applying Solution-Focused Brief Therapy (SFBT) to clients with anxiety issues is the lack of studies and samples. There have been some recent studies on clients with anxiety disorders using different theories and approaches. However, as we see in studies using Solution-Focused Brief Therapy (SFBT), this approach can be considered successful, fast, and reduce the cost of treatment and efficiently implemented on anyone fit.

\section{Conclusion}

The effectiveness of the application of this theory to the diversity of clients is seen to be excellent. As we know, everyone is unique and the approaches used may not be the same for each other even though the issues raised are the same. (Roeden et al., 2011) explained that there was a significant improvement in the aspects of quality of life, maladaptive behavior, and goal attainment samples from those with Mild Intellectual Disabilities through the Solution-Focused Brief Therapy (SFBT) approach. Also, there are differences in aspects of treatment time, and treatment costs can be reduced as results are obtained more quickly through studies conducted on patients with schizophrenia (Panayatov et al.). This therapy has also been applied and its efficacy has been tested in cases involving panic disorder (Kraft, 2012), and deliberate self- harm (Tapolaa et al., 2010).

One possible conclusion is that Solution-Focused Brief Therapy (SFBT) is best applied in a variety of settings, especially requiring fast but effective, low-cost periods such as social agencies offering counseling services, schools, hospitals, prisons, and more. Besides, we can apply it to students, inmates, drug offenders, or drug and alcohol offenders, as well as to miss a sample of patients with mental illness.

\section{References}

Bannink, F. P. (2007). Solution-Focused Brief Therapy. J Contemporary Psychotherapy, 37, 87-94.

Dermer., S. B., Robey, P. A., \& Dunham, S. . (2012). A comparison of Reality Therapy and Choice Theory with Solution-Focused Therapy. International Journal of Choice Theory and Reality Therapy, 31(2).

Kraft, D. (2012). Panic disorder without agoraphobia: A multi-modal approach - Solution- Focused Therapy, Hypnosis and Psychodynamic Psychotherapy. Of Integrative Research, Counselling and Psychotherapy, 1(1).

Roeden, J. M., Maaskant, M. A., Bannink, F. P., \& Curfs, L. M. G. (2011). Solution-Focused Brief Therapy with People with Mild Intellectual Disabilities: A Case Series. Journal of Policy and Practice in Intellectual Disabilities, 8(4).

Sumari, M., Tharbe, I. H. A., Khalid, N. M., \& Nor, A. M. (2014). Teori Kaunseling dan Psikoterapi. Universiti Malaya.

Tapolaa, V., Lappalainen, R., \& Wahlstrom, J. (2010). Brief intervention for deliberate self-harm: an exploratory study. Suicidology. www.suicidology-online.com

Wood, J. J., McLeod, B. D., Piacentini, J. C., \& Sigman, M. (2009). One-year follow-up of family versus child CBT for anxiety disorders: Exploring the roles of child age and parental intrusiveness. Child Psychiatry and Human Development, 40(2), 301-316. 
BISMA The Journal of Counseling

RQSN : Print 2598-3199 - Online 2598-3210

Article Information (Supplementary)

\section{Conflict of Interest Disclosures:}

The authors declare that they have no significant competing financial, professional or personal interests that might have

influenced the performance or presentation of the work described in this manuscript.

Copyrights Holder: $<$ Haron $><2020>$

First Publication Right: BISMA The Journal of Counseling

\section{https://doi.org/10.xxxx/xxxxx}

@creative

Open Access Article I CC-BY Creative Commons Attribution 4.0 International License.

Word Count: 2339 